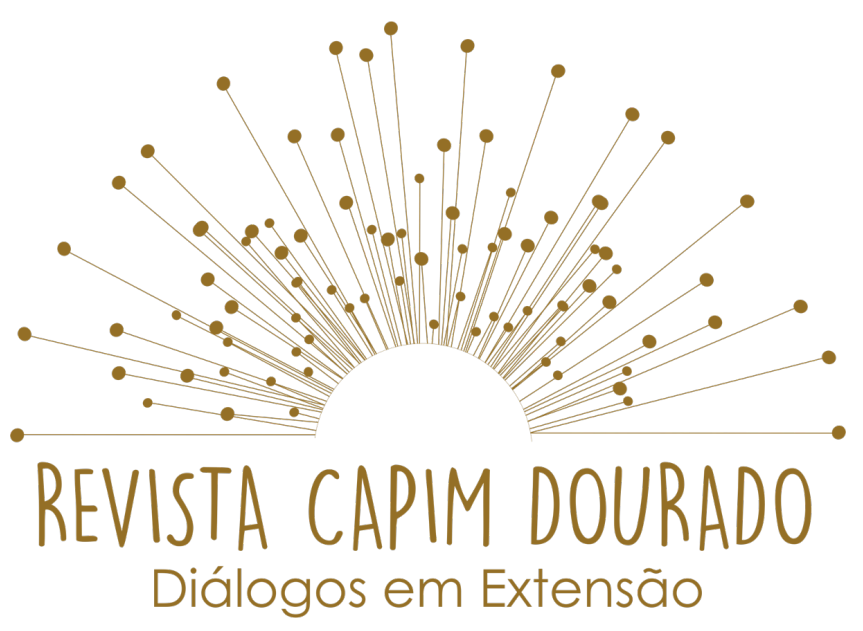

ISSN n² 2595-7341

Vol. 3, n. 1, Janeiro-Abril, 2020

DOI: http://dx.doi.org/10.20873/uft.2595-7341.2020v3n1p143

\title{
PROGRAMA DE ACESSO DEMOCRÁTICO À UNIVERSIDADE E ACOMPANHAMENTO PEDAGÓGICO - PADU/PORTO NACIONAL 2018
}

DEMOCRATIC ACCESS PROGRAM TO THE UNIVERSITY AND PEDAGOGICAL FOLLOW-UP - PADU / PORTO NACIONAL 2018

PROGRAMA DE ACCESO DEMOCRÁTICO A LA UNIVERSIDAD Y SEGUIMIENTO PEDAGÓGICO - PADU / PORTO NACIONAL 2018

\author{
Ricardo Ferreira de Sousa ${ }^{1}$ \\ Matheus Silva Falcão ${ }^{2}$ \\ Rafael da Silva Lisboa ${ }^{3}$ \\ Wedster Felipe Martins Sabino 4 \\ Radamés Vieira Nunes ${ }^{5}$
}

\section{RESUMO}

A extensão universitária é considerada como um dos pilares da educação no Brasil, associando a formação profissional e humanística e também no ensejo da transformação social-político-cultural. O presente relato é fruto de uma ação

\footnotetext{
${ }^{1}$ Graduação em Letras - Língua Portuguesa e Literaturas pela Universidade Federal do Tocantins (UFT), Porto Nacional, Tocantins. ricardof@mail.uft.edu.br.

${ }^{2}$ Graduação em História pela Universidade Federal do Tocantins (UFT), campus Porto Nacional, Tocantins. falcaomatheus.7@gmail.com.

${ }^{3}$ Graduação em Letras - Língua Portuguesa e Literaturas pela Universidade Federal do Tocantins (UFT), campus Porto Nacional, Tocantins. rafaelletras19@gmail.com.

${ }^{4}$ Graduando em História, pela Universidade Federal do Tocantins (UFT), campus Porto Nacional, Tocantins. wedster.sabino@mail.uft.edu.br.

${ }^{5}$ Professor Doutor adjunto do curso de História da Universidade Federal do Tocantins (UFT) e coordenador do Programa de Apoio Democrático à Universidade e Apoio Pedagógico (PADU), Porto Nacional, Tocantins. radamesnunes@mail.uft.edu.br.
} 


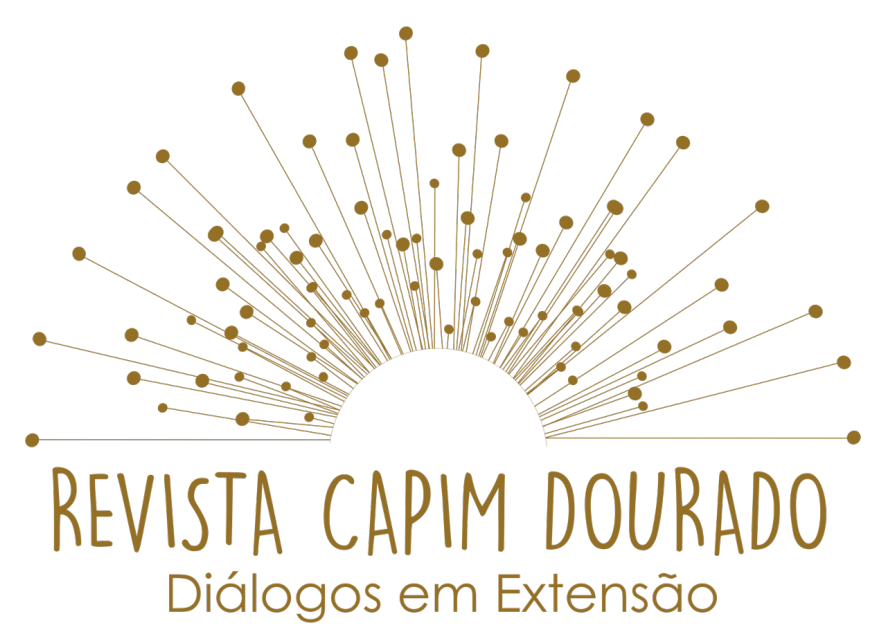

ISSN n² 2595-7341

Vol. 3, n. 1, Janeiro-Abril, 2020

DOI: http://dx.doi.org/10.20873/uft.2595-7341.2020v3n1p143

realizada no Projeto de Extensão Programa de Acesso Democrático à Universidade e Apoio Pedagógico, vinculado à Universidade Federal do Tocantins, campus universitário de Porto Nacional, estado do Tocantins. A ação consiste no preparo de jovens para as provas do Exame Nacional do Ensino Médio, sendo que os professores ministrantes são acadêmicos de cursos superiores de licenciatura da instituição, no anseio de torna-los de frente e atuante na prática docente, aplicando àquilo que foi apreendido na academia. Diante disso, atuar no projeto de extensão, nos proporciona autoconfiança e conhecimento da prática docente, melhorando o nosso currículo e aumentando as chances para o mercado de trabalho, além de contribuir para desenvolvimento da comunidade, oportunizando a entrada no ensino superior.

PALAVRAS-CHAVE: Educação. Enem. Formação de Professores.

\section{ABSTRACT}

University extension is considered as one of the pillars of education in Brazil, associating professional and humanistic training and also in the opportunity for social-political-cultural transformation. This report is the result of an action carried out in the Project for the Extension of the Democratic Access to University and Pedagogical Support Program, linked to the Federal University of Tocantins, university campus of Porto Nacional, state of Tocantins. The action consists of preparing young people for the exams of the National High School Exam, and the teaching professors are academics of higher education courses at the institution, in the desire to make them face and active in teaching practice, applying to what was apprehended in the gym. Therefore, acting in the extension project, provides us with self-confidence and knowledge of teaching practice, improving our curriculum and increasing the chances for the job market, in addition to contributing to the development of the community, enabling the entry into higher education. 


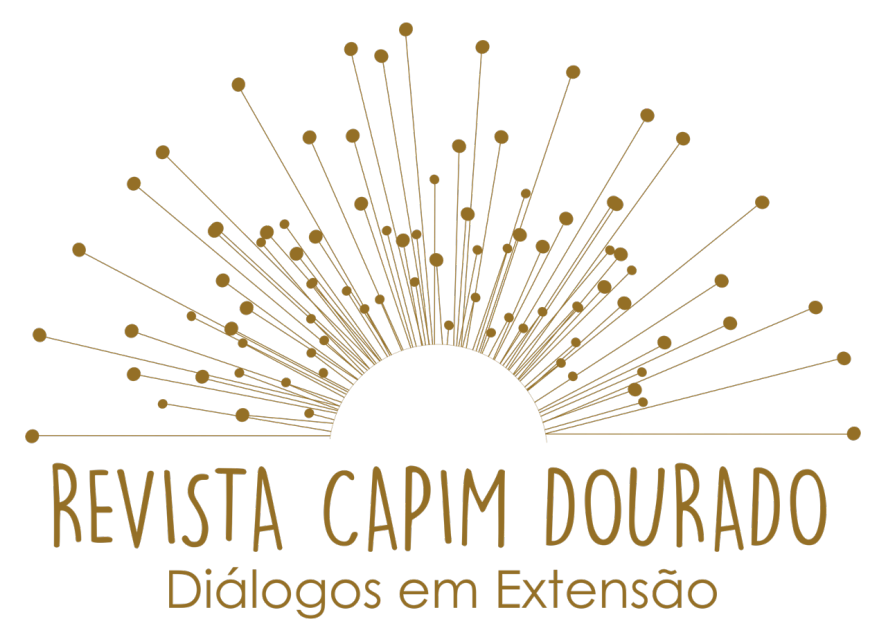

ISSN n² 2595-7341

Vol. 3, n. 1, Janeiro-Abril, 2020

DOI: http://dx.doi.org/10.20873/uft.2595-7341.2020v3n1p143

KEYWORDS: Education. And either. Teacher training.

\section{RESUMEN}

La extensión universitaria es considerada como uno de los pilares de la educación en Brasil, asociando la formación profesional y humanística y también en la oportunidad de transformación socio-político-cultural. Este informe es el resultado de una acción realizada en el Proyecto de Extensión del Acceso Democrático a la Universidad y Programa de Apoyo Pedagógico, vinculado a la Universidad Federal de Tocantins, campus universitario de Porto Nacional, estado de Tocantins. La acción consiste en preparar a los jóvenes para los exámenes del Examen Nacional de Bachillerato, y los profesores docentes son académicos de los cursos de educación superior de la institución, en el afán de hacerlos rostros y activos en la práctica docente, aplicando lo que fue aprehendido en el gimnasio. Por tanto, actuar en el proyecto de extensión, nos aporta confianza en nosotros mismos y conocimiento de la práctica docente, mejorando nuestro currículo y aumentando las oportunidades para el mercado laboral, además de contribuir al desarrollo de la comunidad, posibilitando el ingreso a la educación superior.

PALABRAS CLAVE: Educación. Y también. Formación de profesores.

Recebido em: 01.10.2019. Aceito em: 09.10.2019. Publicado em: 01.01.2020. 


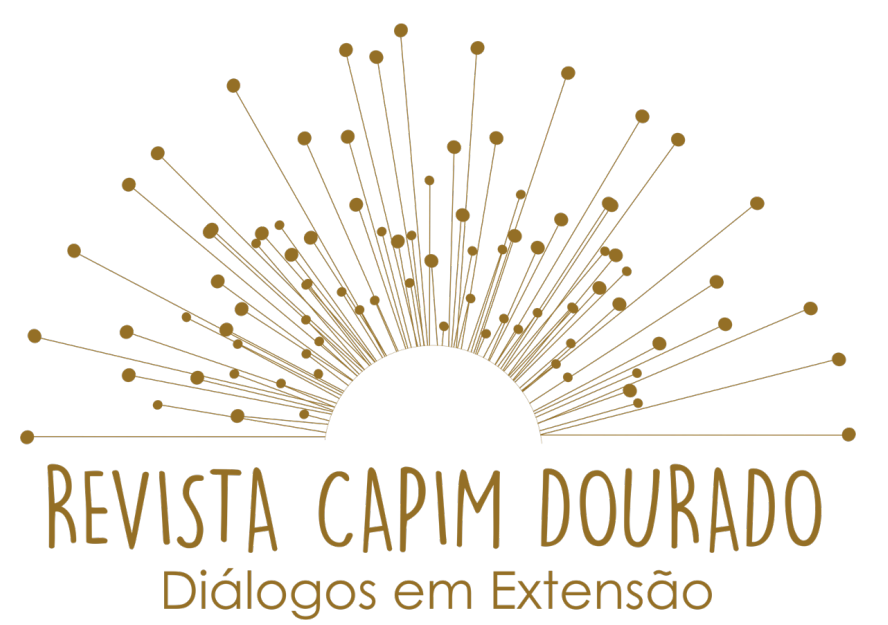

ISSN n² 2595-7341

Vol. 3, n. 1, Janeiro-Abril, 2020

DOI: http://dx.doi.org/10.20873/uft.2595-7341.2020v3n1p143

\section{INTRODUÇÃO}

O Programa de Acesso Democrático à Universidade e Apoio Pedagógico (PADU) é um programa criado e conduzido pela comunidade acadêmica da Universidade Federal do Tocantins (UFT), envolvendo especialmente docentes e acadêmicos, com a finalidade de oferecer cursos preparatórios para o Exame Nacional do Ensino Médio (ENEM) e vestibulares convencionais, destinados, sobretudo à população de baixa renda. O PADU surgiu em Porto Nacional em 2003 com o nome de Centro de Apoio Popular Estudantil do Tocantins (CAPETINS). Desde sua criação o Programa se baseia no princípio da responsabilidade social para minimizar as consequências de um processo histórico excludente que dificulta o acesso a Universidade para uma parte significativa da sociedade. Em parceria com escolas de ensino médio da rede pública de educação, o programa oferece dois cursos para a edição de 2018: um que funciona de segunda a quinta-feira no período noturno e outro que funciona aos sábados no período vespertino.

Além dos cursos preparatórios, com realização de aulão e simulados, a equipe do programa oferece outras atividades que permitem a aproximação da universidade com a comunidade. Dentre as quais a visita guiada ao campus para apresentar aos cursistas toda estrutura da universidade bem como os cursos disponíveis, além do plantão de apoio para auxiliar os interessados na realização da inscrição e pedido de isenção para os processos seletivos. A equipe acompanha os cursistas da preparação até a entrada na Universidade. Nesse 


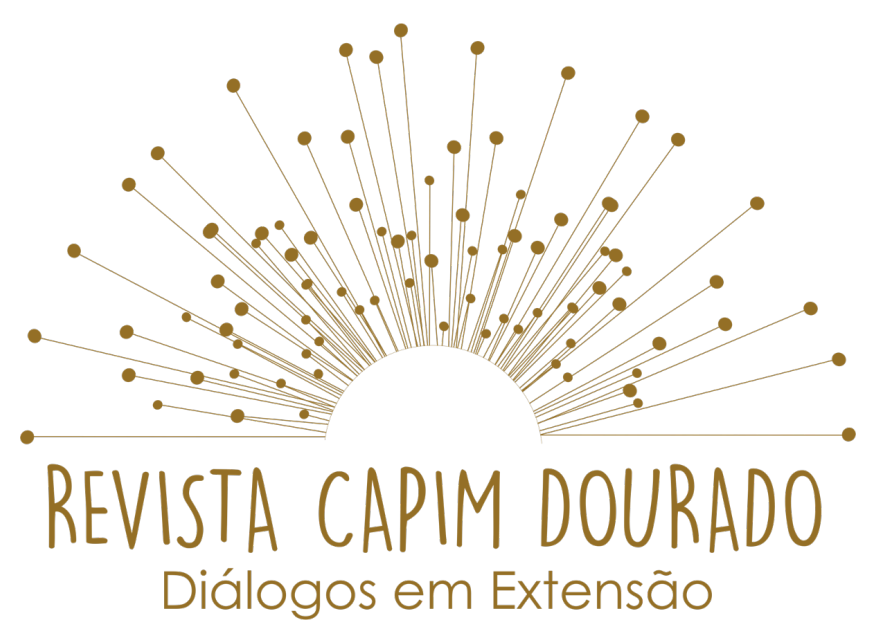

ISSN n² 2595-7341

Vol. 3, n. 1, Janeiro-Abril, 2020

DOI: http://dx.doi.org/10.20873/uft.2595-7341.2020v3n1p143

sentido, o programa cumpre dupla função: a de proporcionar aos acadêmicos um maior contato com a prática docente e a outra permite ampliar aos cursistas a possibilidade de acesso à Universidade Pública.

O núcleo do programa relatado neste trabalho corresponde ao projeto do Campus de Porto Nacional, região central do estado e estruturada em duas frentes de ação. A primeira está abrigada no Centro de Ensino Médio Felix Camoa, e a segunda no Colégio Estadual Angélica Ribeiro Aranha. As experiências relatadas aqui estão ligadas a segunda frente de ação do programa, executadas em sua totalidade por voluntários, com o apoio e coordenação das instituições.

\section{METODOLOGIA}

A divulgação se deu através da visita dos professores-monitores, juntamente com o coordenador do programa aos Colégios e também por meio das redes sociais. Ao final do período recebemos 97 inscrições. Aproximadamente $60 \%$ das inscrições foram de estudantes concluintes do Ensino Médio e $40 \%$ de egressos, todos oriundos da rede pública de ensino. A princípio, o Programa atuaria somente no Centro de Ensino Médio Félix Camoa. A iniciativa de trabalhar em duas frentes nasce na busca por apoio de um dos professores egresso do Curso de Licenciatura em História da UFT - do Colégio Angélica Aranha que, com o auxílio de acadêmicos, havia idealizado outro projeto intitulado "Quero Ser Um Universitário". 


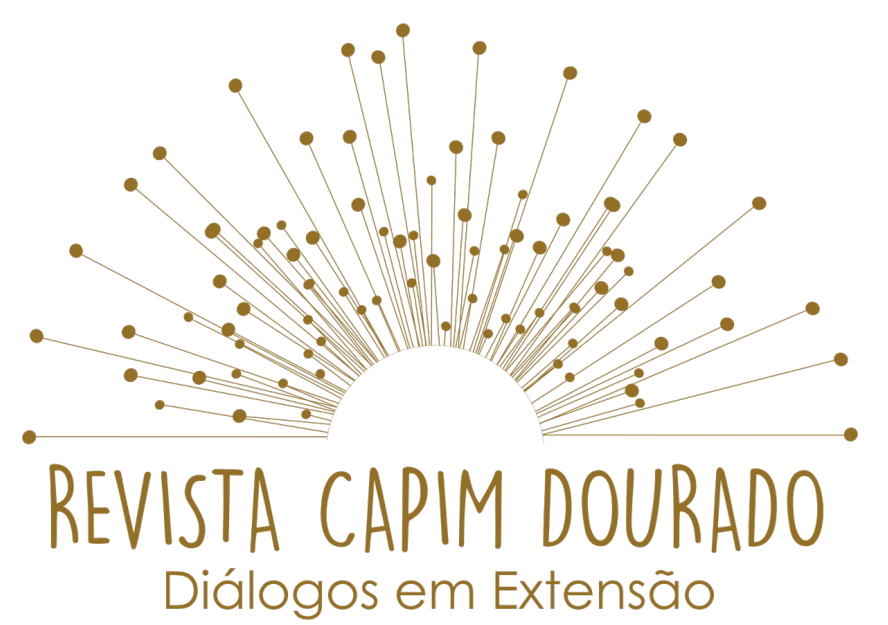

ISSN n² 2595-7341

Vol. 3, n. 1, Janeiro-Abril, 2020

DOI: http://dx.doi.org/10.20873/uft.2595-7341.2020v3n1p143

Diante disso, com o intuito de fortalecer o projeto, surge a ideia da união entre Universidade e Colégio, acoplando-o ao PADU e ao Programa de Apoio ao Discente Ingressante (PADI), buscando dar maior estrutura ao "Quero Ser Um Universitário". Com a união das iniciativas, houve um fortalecimento das ações, bem como do acompanhamento pedagógico, logístico e estrutural das instituições aos professores-voluntários.

As ações tiveram início em Março de 2018, com reuniões semanais de planejamento, no Campus da UFT, bem como nas dependências da Escola Angélica Aranha. Já a equipe que atuou no Cem Félix Camoa iniciou a preparação em Março e as aulas em Agosto. $O$ espaço escolhido para abrigar as aulas foram as respectivas escolas, no intuito de facilitar o acesso aos estudantes e dos membros da comunidade interessados em participar. Na primeira escola as aulas ocorreram aos sábados, das catorze às dezessete horas, abrangendo uma área do conhecimento por semana, ministradas por no mínimo dois professoresmonitores. Na segunda escola as aulas ocorreram de segunda a quinta-feira no período noturno, das $19 \mathrm{~h} 00 \mathrm{~min} \mathrm{~h}$ às $22 \mathrm{~h} 00 \mathrm{~min} \mathrm{~h}$. Algumas aulas foram realizadas nos laboratórios da Universidade.

\section{RESULTADOS FINAIS}

Durante a aplicação das aulas, o Programa se manteve com uma frequência média de $50 \%$ do total de matriculados. A evasão foi baixa, tendo em vista que boa parte dos inscritos não evadiu já que nunca compareceram nas 


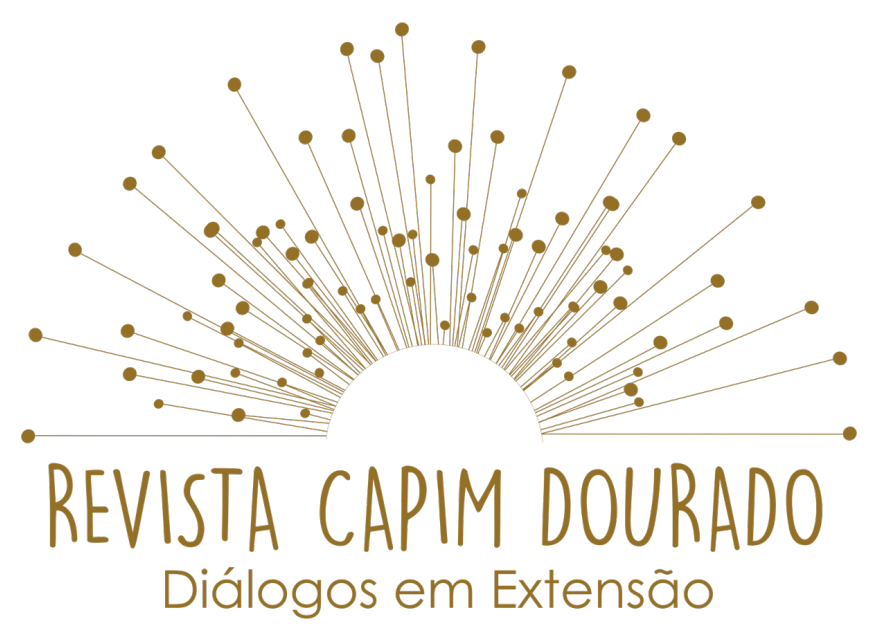

ISSN n² 2595-7341

Vol. 3, n. 1, Janeiro-Abril, 2020

DOI: http://dx.doi.org/10.20873/uft.2595-7341.2020v3n1p143

aulas. Os inscritos frequentes participaram até o final do curso preparatório oferecido pelo programa. Os setores que integram a comunidade atendida pelos Colégios foram: Setor Imperial, Alto da Colina, Padre Luso, Parque Eldorado, Setor Vila Nova, Jardim América, Jardim Umuarama, Novo Horizonte e Nova Capital. A maioria dos setores são os mais periféricos de Porto Nacional, os cursistas, em sua maioria, são oriundos de famílias com baixa renda implicados pelas condições socioeconômicas, que afeta inclusive o desempenho escolar. A ação ocorreu conforme o planejado e teve retorno satisfatório, que pode ser evidenciado pelo envolvimento dos cursistas.

\section{CONSIDERAÇÕES FINAIS}

O PADU, do campus de Porto Nacional, tem buscado através das atividades do programa minimizar as desigualdades e a exclusão do acesso ao ensino superior. O PADU e toda a equipe envolvida na realização do curso preparatório, juntamente com as escolas parceiras, aguardamos otimistas pelos resultados dos cursistas nos vestibulares e no Exame Nacional do Ensino Médio. Mais que os resultados nos processos seletivos, nossa meta foi compartilhar com a comunidade uma educação que seja de fato transformadora.

\section{REFERÊNCIAS}




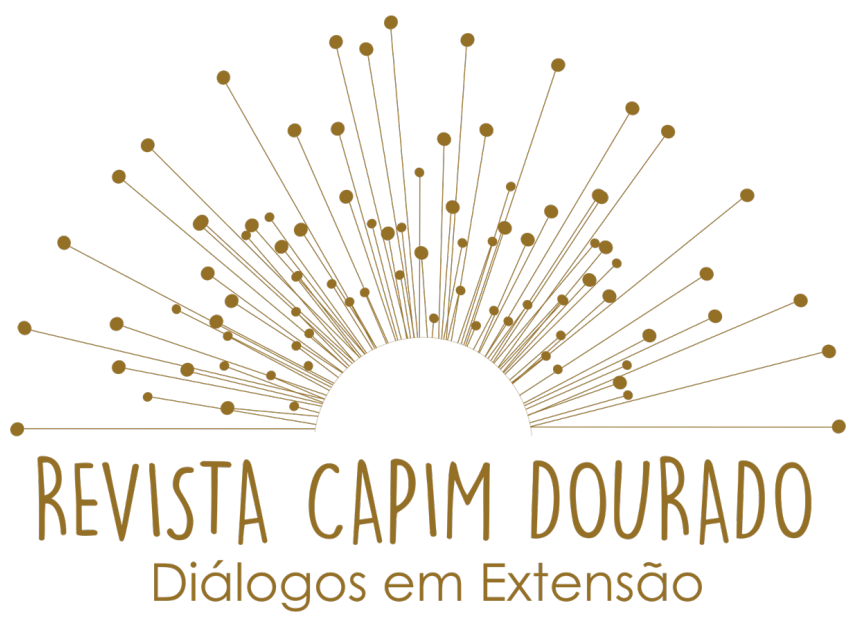

ISSN n² 2595-7341

Vol. 3, n. 1, Janeiro-Abril, 2020

DOI: http://dx.doi.org/10.20873/uft.2595-7341.2020v3n1p143

CONSEPE - UFT. Decreto $n^{\circ}$ 09, de 15 de Abril de 2015. Dispõe sobre a normatização dos Programas Institucionais: Programa de Acesso Democrático à Universidade (PADU) e Programa de Acesso Democrático de Indígenas e Quilombolas (PADIQ). Palmas, TO, Abril 2015.

NUNES, E.; PEREIRA, I.; PINHO, M. A responsabilidade social universitária e a avaliação institucional: reflexões iniciais. Avaliação. Campinas, v. 22, n. 1, p. 165177, mar. 2017. 